Article

\title{
Evaluation of Artificial Neural Network-Based Temperature Control for Optimum Operation of Building Envelopes
}

\author{
Jin Woo Moon ${ }^{1}$, Ji-Hyun Lee ${ }^{2}$ and Sooyoung Kim ${ }^{3, *}$ \\ 1 Department of Building \& Plant Engineering, Hanbat National University, Daejeon 305-719, Korea; \\ E-Mail: jwmoon@hanbat.ac.kr \\ 2 Graduate School of Culture Technology, Korea Advanced Institute of Science \& Technology, \\ Daejeon 305-701, Korea; E-Mail: jihyunlee@kaist.ac.kr \\ 3 Department of Interior Architecture \& Built Environment, Yonsei University, Seoul 120-749, Korea \\ * Author to whom correspondence should be addressed; E-Mail: sooyoung@yonsei.ac.kr; \\ Tel.: +82-2-2123-3142; Fax: +82-2-313-3139.
}

External Editor: Stephen Treado

Received: 15 June 2014; in revised form: 27 August 2014 / Accepted: 28 October 2014 /

Published: 12 November 2014

\begin{abstract}
This study aims at developing an indoor temperature control method that could provide comfortable thermal conditions by integrating heating system control and the opening conditions of building envelopes. Artificial neural network (ANN)-based temperature control logic was developed for the control of heating systems and openings at the building envelopes in a predictive and adaptive manner. Numerical comparative performance tests for the ANN-based temperature control logic and conventional non-ANN-based counterpart were conducted for single skin enveloped and double skin enveloped buildings after the simulation program was validated by comparing the simulation and the field measurement results. Analysis results revealed that the ANN-based control logic improved the indoor temperature environment with an increased comfortable temperature period and decreased overshoot and undershoot of temperatures outside of the operating range. The proposed logic did not show significant superiority in energy efficiency over the conventional logic. The ANN-based temperature control logic was able to maintain the indoor temperature more comfortably and with more stability within the operating range due to the predictive and adaptive features of ANN models.
\end{abstract}


Keywords: temperature controls; thermal environment; artificial neural network (ANN); predictive and adaptive control; building envelope; energy efficiency

\section{Introduction}

Buildings covered with curtain wall structures have normally been used to construct high-rise commercial buildings and can reduce the building structural loads. However, curtain wall structure buildings with a single skin envelope (SSE) have weak envelope insulation and controlling the penetration of solar irradiance in the indoor space can be difficult. Therefore, a single skin envelope is not optimal for controlling the indoor thermal environment or energy efficiency. Accordingly, heating and cooling loads in commercial buildings are increased due to the low insulation level between the outdoor and indoor environment. Additionally, the amount of heat transfer which results in energy transfer varies unpredictably according to the diverse changes in outdoor weather conditions.

In order to reduce the energy transfer between the outdoor environment and indoor space, a double skin envelope (DSE) has been applied to building facades. Previous studies proved that the double skin envelope effectively contributed to reducing heating and cooling energy consumption. The design and perspectives of the double skin envelope and its performance according to the solar controls, natural ventilation, shading device, solar photovoltaic, active facades such as active window strategies, glass selection, and cavity depth were evaluated [1,2]. Diverse performance tests presented the effectiveness of double skin envelope for saving heating and cooling energy based on the proper ventilation strategies [3-6]. In particular, besides the remarkable reduction of the heating energy, cooling energy was also significantly saved compared to the singles skin enveloped-buildings when the natural ventilation strategy or the passive thermal mass was applied [6,7].

The primary contributor for energy savings was the cavity space between the internal and external envelope, which functions as a thermal buffer zone for controlling energy transfer between the outdoor and indoor environments. The secondary contributor was the appropriate control of openings installed in the internal and external envelopes. Thus, the advantages of a double skin envelope can be intensified when the relevant components of energy transfer between indoor and outdoor space are properly installed and controlled. For example, envelopes with glass that has strong heat resistance and adequately operating shading devices are able to control the amount of convective and radiative heat transferred through the envelope. The opening conditions of internal and external envelopes also effectively contribute to determine the amount of convective heat transfer by controlling airflows between outdoor and indoor spaces.

Therefore, the opening conditions of envelopes are strongly related to changes in indoor temperature, which is a critical factor for occupants' thermal comfort in indoor spaces. In order to determine proper control strategies for the opening conditions, studies have been conducted for various building and weather conditions [8]. The studies revealed that rule-based controls are the most widespread control methods, owing to their simplicity in developing algorithms and applications for actual buildings. A specific rule is employed to the rule-based methods to determine the opening conditions based on the relevant factors, such as the indoor and cavity temperatures. Accordingly, this specific rule controls the amount of heat transfer by conduction, ventilation, and solar radiation. 
For effective thermal control of buildings, the artificial neural network (ANN) technique, which is analogous to the human neural structure, has been applied increasingly to the thermal control field due to its outstanding predictability and adaptability [9]. The ANN model predicts future thermal conditions based on the current and past conditions, so the work of the thermal control systems can be predetermined. In addition, the iterative training process for the ANN model is designed to adapt itself to the new environments around buildings. Through this predictability and adaptability, the ANN-based control logic can provide a more comfortable and stable thermal environment. Its superiority over mathematical methods, such as regression models or proportional-integral-derivative (PID) controllers has been proven based on aspects of thermal comfort and energy efficiency [10-17].

Recently, ANN-based residential thermal control methods to optimize residential heating, cooling, humidifying, and dehumidifying system control have been proposed [10]. A comparative analysis with a conventional control method revealed that the proposed ANN-based method demonstrated more effective thermal control than the conventional control method. For example, the indoor temperature was better stabilized within specified comfort ranges (e.g., $23-26{ }^{\circ} \mathrm{C}$ in summer and $20-23{ }^{\circ} \mathrm{C}$ in winter) and overshoot and undershoot outside of the comfort ranges were significantly reduced.

Despite the potential of rule-based control methods, the proposed methods in previous studies have two limitations that should be considered carefully. Firstly, the thermal criteria to determine the opening conditions of the internal and external envelopes were intuitively selected. In many cases, the air temperature in the cavity space and the amount of solar radiation functioned as major determinants. In comparison, other diverse thermal factors such as outdoor and indoor air temperature, which are related to double skin envelope opening operations, were not considered.

Secondly, integrated thermal control logic has not yet been proposed. The heating or cooling systems are normally operated based on the current air temperature, while openings in the double skin envelope are independently controlled based on the cavity air temperature. Thus, their interactive effects have not been considered for better thermal comfort with improved energy efficiency. The integrated logic, therefore, need to be developed for comprehensively controlling the opening conditions of internal and external envelopes and the thermal control devices such as heating and cooling systems.

The purpose of this study is to develop effective control methods for indoor air temperature to optimize thermal comfort. Temperature control logic to control heating systems and opening of building envelopes has been developed in this study. The current working state of the heating system and the opening conditions of the envelopes function as important components to determine the indoor air temperature conditions in the control logic. Specifically, the ANN models were developed and applied for the predictive and adaptive controls in the control logic. The ANN models employed a series of input variables which were strongly related to indoor temperature conditions. Thus, the opening conditions for the double skin enveloped building and single skin enveloped building can be determined in a more comprehensive manner.

Using the predicted indoor air temperature for the various opening strategies, the control logic determines the optimal opening strategy and predetermines heating system operation. The control logic also works accurately in response to changes or disturbances around double skin enveloped buildings, since the ANN model employs the sliding-window method for training data management. 


\section{Development of Integrated Artificial Neural Network-Based Temperature Control Logic}

\subsection{Temperature Control Logic}

The proposed temperature control logic was designed to maintain indoor temperature within a comfortable range based on integrated control for openings of building envelopes and heating system. Figure 1 describes a conceptual flow of the process that incorporates the ANN model and the control logic for temperature control in double skin enveloped buildings and single skin enveloped buildings.

Figure 1. Incorporative process between the artificial neural network (ANN) model and control logic.

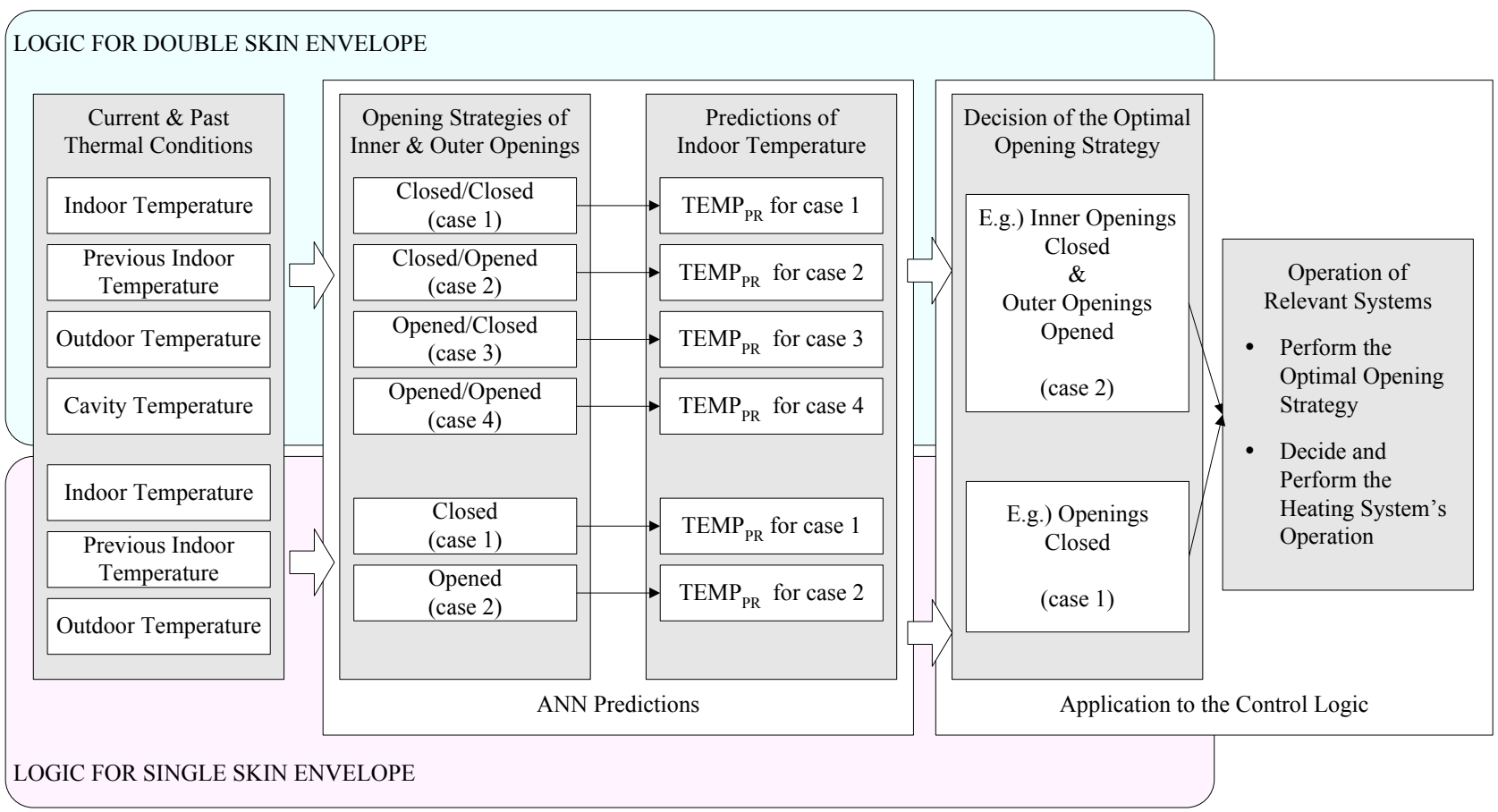

Three steps are employed for the double skin enveloped buildings. The first step is a data gathering process that collects the current and past thermal conditions such as current indoor temperature, previous indoor temperatures, outdoor temperature, and cavity temperature. The data collected in this step are used as input variables in the ANN models.

The second step is to predict future indoor temperature conditions based on the ANN models. Four future indoor temperatures are predicted for the four opening strategies of the internal and external envelopes of the double skin envelopes. Four independent ANN models are applied to predict the future indoor temperature condition that is the amount of air temperature overshoot or undershoot (TEMP $\mathrm{PR}$ ). The amount of overshoot or undershoot is the maximum rise or drop when the current working mode of the heating device is changed. For example, the overshoot of the air temperature is the maximum rise of air temperature after the heating device that is working is stopped.

The third step is to decide the optimal opening strategy and operate relevant systems. Using the four predicted ANN model values for the four opening strategies, temperature control logic determines the optimal opening strategy of the internal and external envelope openings. In this process, the opening strategy and the current working mode of the heating device are considered in an integrated manner. 
For example, when a heating device is working, the optimal opening strategy for internal and external envelopes is to provide the largest overshoot of the indoor temperature. If the predicted overshoots of the indoor temperature by the ANN models for the four opening strategies are $+1.7{ }^{\circ} \mathrm{C}$ (case 1), $-0.3{ }^{\circ} \mathrm{C}$ (case 2), $+0.2{ }^{\circ} \mathrm{C}$ (case 3 ), and $-1.1{ }^{\circ} \mathrm{C}$ (case 4), then the optimal strategy is case 1 , where the openings at internal and external envelopes are closed.

Employing case 1 for the openings, the heating device can be turned off earlier than in other cases, which keeps the indoor air temperature within a comfortable range. Similarly, when the heating system is not working, the optimal opening strategy is the case that provides the least undershoot of indoor temperature. By employing this optimal strategy, indoor air temperature can be conditioned more comfortably and energy consumption can be minimized to maintain a thermal environment within a comfortable range. The operation of the heating device and the optimal strategy for opening are conducted based on the decisions that are determined by this process.

Figure 2 presents the temperature control logic which was developed based on the process that incorporated the ANN model. Four ANN models predict the indoor temperature for the four opening strategies in the double skin enveloped buildings while two ANN models are applied in the single skin enveloped buildings. Considering the current working mode of the heating device, the optimal opening strategy is determined. After comparing the process between the summation of current (TEMPIN) and predicted $\left(T E M P_{\mathrm{PR}}\right)$ temperatures and the operating range of the systems, the new working mode of the heating system is determined and the optimal opening strategy is conducted.

Figure 2. ANN-based temperature control logic for double and single skin envelope.

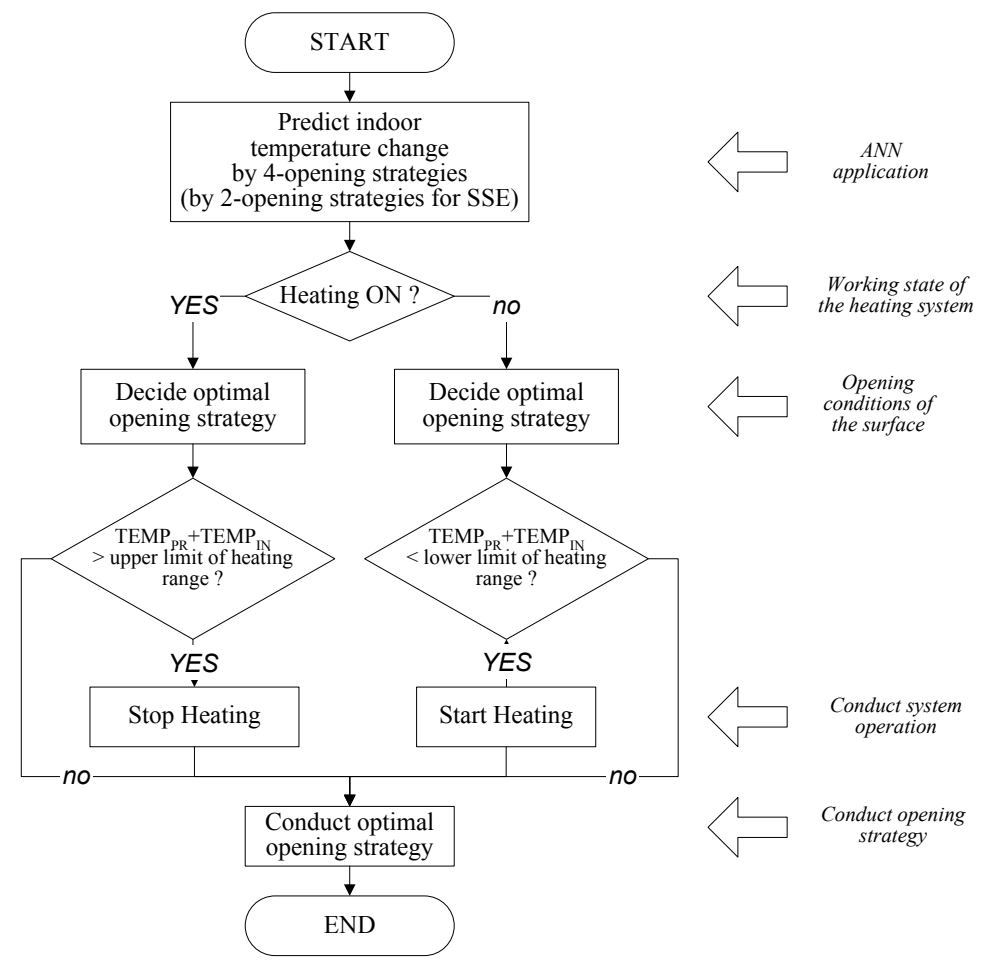

\subsection{Artificial Neural Network Model}

Two ANN models were developed to predict the overshoot and undershoot of the indoor air temperature in double skin enveloped buildings and single skin enveloped buildings, respectively. 
Three major advantages can be guaranteed by applying the ANN models in the control logic. Firstly, the indoor temperature conditions will be controlled in an integrated manner. Secondly, relevant factors, which were demonstrated to statistically affect the indoor temperature, can be selected as determinants for opening of the envelopes. Finally, the predictive and adaptive controls are feasible.

Figures 3 and 4 show the structures of the two developed ANN models for single and double skin enveloped buildings. One input layer, four hidden layers, and one output layer comprise each ANN model. Detailed conditions for the variables are listed in Table 1.

Figure 3. A structure of ANN models for buildings with double skin envelopes.

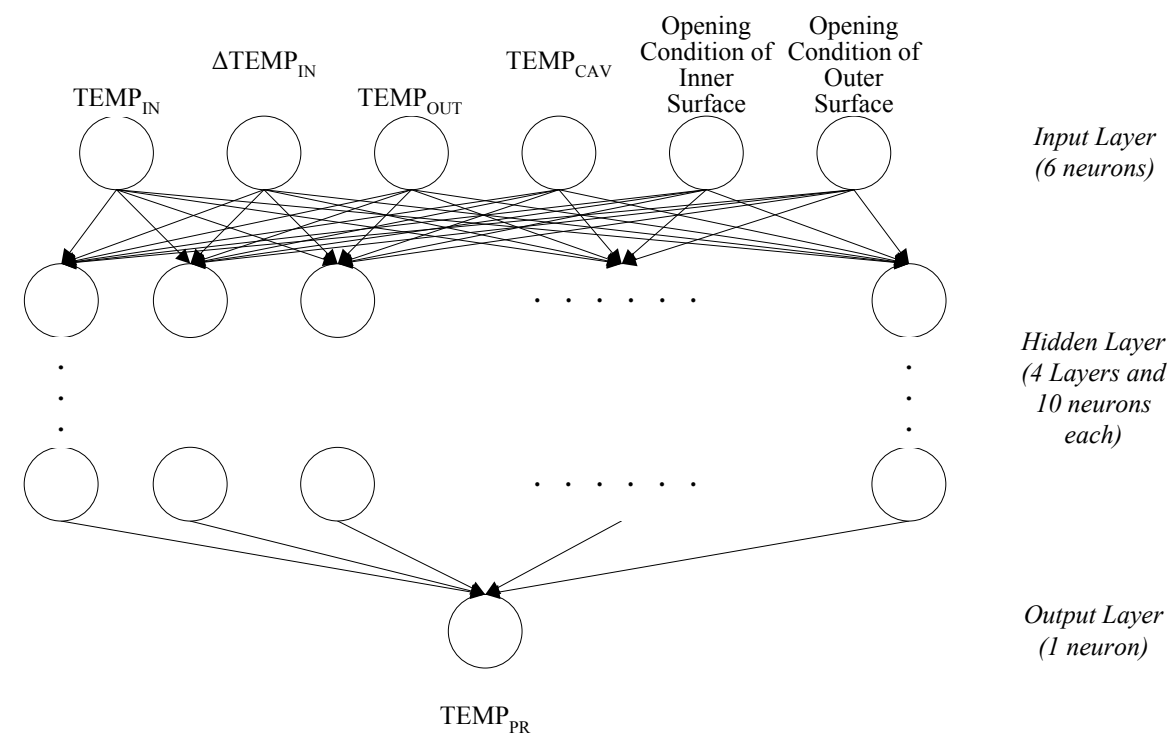

Figure 4. A structure of ANN models for buildings with single skin envelopes.

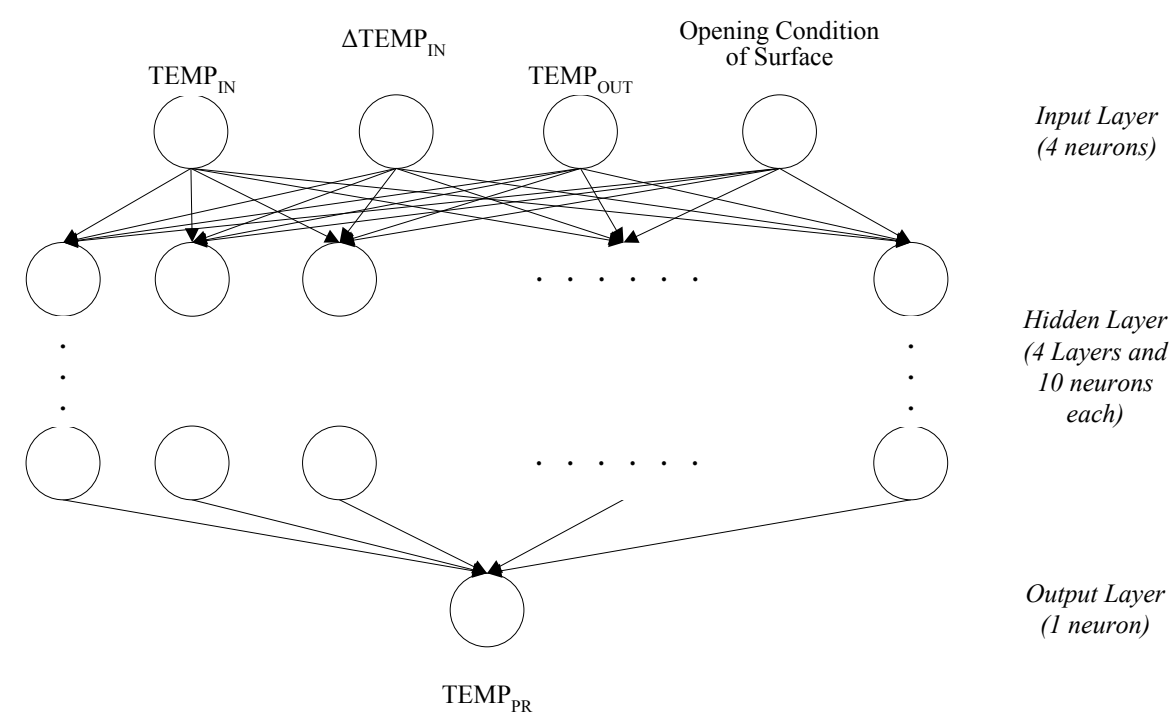


Table 1. Composition of the developed ANN model.

\begin{tabular}{|c|c|c|c|}
\hline Comp & nents & Double skin envelope (DSE) [8] & Single skin envelope (SSE) \\
\hline \multirow[t]{3}{*}{$\begin{array}{c}\text { Layer } \\
\text { composition }\end{array}$} & Input layer & $\begin{array}{l}\text { - Number of layers: } 1 \\
\text { - } N_{\mathrm{i}}: 6 \\
\text { (i) } T E M P_{\mathrm{IN}}:-10-40{ }^{\circ} \mathrm{C} \\
\text { (ii) } \triangle T E M P_{\mathrm{IN}}:-10-10{ }^{\circ} \mathrm{C} \\
\text { (iii) } T E M P_{\mathrm{OUT}}:-20-40^{\circ} \mathrm{C} \\
\text { (iv) } T E M P_{\mathrm{CAV}}:-20-80{ }^{\circ} \mathrm{C} \\
\text { (v) opening conditions of internal } \\
\text { envelope: } 0 \text { (closed), } 1 \text { (opened) } \\
\text { (vi) opening conditions of external } \\
\text { envelope: } 0 \text { (closed), } 1 \text { (opened) }\end{array}$ & $\begin{array}{l}\text { - Number of layers: } 1 \\
\text { - } N_{\mathrm{i}}: 4 \\
\text { (i) } T E M P_{\mathrm{IN}}:-10-40{ }^{\circ} \mathrm{C} \\
\text { (ii) } \triangle T E M P_{\mathrm{IN}}:-10-10{ }^{\circ} \mathrm{C} \\
\text { (iii) } T E M P_{\mathrm{OUT}}:-20-40{ }^{\circ} \mathrm{C} \\
\text { (iv) opening conditions of } \\
\text { envelope: } 0 \text { (closed), } 1 \text { (opened) }\end{array}$ \\
\hline & Hidden layer & $\begin{array}{l}\text { - Number of layers: } 4 \\
\text { - } N_{\mathrm{h}}: 10\end{array}$ & - Same as DSE \\
\hline & Output layer & $\begin{array}{l}\text { - Number of layers: } 1 \\
\left.\text { - } N_{\mathrm{o}}: 1 \text { (TEMP }{ }_{\mathrm{PR}}\right) \\
\end{array}$ & - Same as DSE \\
\hline \multicolumn{2}{|c|}{ Training methods } & $\begin{array}{l}\text { - Learning rate: } 0.75 \\
\text { - Moment: } 0.30 \\
\text { - Algorithm: Levenberg-Marquardt } \\
\text { - Training goals: } 0.01 \mathrm{~K}^{2} \text { for air } \\
\text { temperature (MSE) } \\
\text { - Epoch: } 1000 \text { times } \\
\text { - Data Managing Technique: } \\
\text { sliding-window method } \\
\text { - } N_{\mathrm{d}}: 43 \\
\text { using } N_{\mathrm{d}}=\left(N_{\mathrm{h}}-\left(N_{\mathrm{i}}+N_{\mathrm{o}}\right) / 2\right)^{2}[18] \\
\end{array}$ & $\begin{array}{l}\text { - Same as DSE } \\
\text { - } N_{\mathrm{d}}: 75 \\
\text { using } N_{\mathrm{d}}=\left(N_{\mathrm{h}}-\left(N_{\mathrm{i}}+N_{\mathrm{o}}\right) / 2\right)^{2}[18]\end{array}$ \\
\hline \multicolumn{2}{|c|}{ Transfer functions } & $\begin{array}{l}\text { - Tangent Sigmoid for hidden neurons } \\
\text { - Pure Linear for output neuron }\end{array}$ & - Same with DSE \\
\hline
\end{tabular}

The number of hidden layers was derived in the previous study, which conducted an optimization process to find the number of hidden layers, number of neurons in the hidden layers, learning rate and moment [8]. The purpose of the previous study was to develop an ANN model and the process was focused purely on finding the optimal parameters of the model. Based on the analysis, an optimal number of hidden layer, number of neurons in the hidden layer, learning rate and moment were found. However, the performance test of the logic was not conducted yet. In this study, the performance of the developed logic was tested for buildings with single and double skin envelopes employing the optimized ANN model. This study deals with the actual application of the control logic which employed the previously mentioned optimized ANN model.

Heat transfer between indoor and outdoor environments was considered to determine the input neurons. Heat transfer is basically composed of conduction and convection (ventilation and infiltration) through the envelope, solar radiation, and internal loads. The amount of heat transfer by conduction and convection is related to the outdoor, cavity, and indoor temperatures as well as the opening conditions of the internal and external envelopes of double skin enveloped buildings. 
In addition, the amount of solar radiation is determined by the solar irradiance to the envelope from the sun and sky surface. These relevant components were selected as initial input variables. However, internal loads were not considered to be an input variable since their amount normally changes according to occupant behaviors. The amount of air temperature change from the previous control cycle, which was assigned as $1 \mathrm{~min}$ in this study, was selected as one of the input variables based on the suggestions in the previous study [10].

Statistical tests conducted in the previous study revealed that the correlation between indoor temperature and solar irradiance was insignificant [19,20]. For example, the coefficient of determination $\left(r^{2}\right)$ was 0.0853 for clear sky, 0.0060 for partly cloudy sky, and 0.0204 for overcast sky. Thus, solar radiation was excluded from the input variables of the final ANN model in this study. The actual values of input variables in Table 1 were normalized to have values between 0 and 1 using Equation (1):

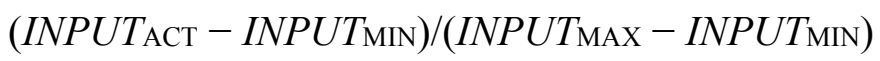

Like the number of hidden layers, the number of neurons in the hidden layer was determined based on the previous optimization process [8]. In the optimization process, the optimal number of neurons in the hidden layers 10 for producing the most accurate outputs was determined to be. The output variable was the predicted indoor temperature (TEMP $\mathrm{PR})$.

Adopted training methods are summarized in Table 1 . The learning rate $(0.75)$ and moment $(0.30)$ for training, respectively, were determined based on the optimization process [8]. In particular, the sliding window method was applied for managing the training data sets. Thus, when the new training data set was acquired, it replaced the oldest set in order to reflect the latest conditions in the ANN model. Initial training data sets were collected from the simulation results conducted before the main tests. Tangent sigmoid and pure linear transfer functions were used in the hidden and output neurons, respectively.

\section{Performance Tests of Artificial Neural Network-Based Temperature Control Logic}

\subsection{Computation Software and Validation}

The developed ANN-based temperature control logic performance was numerically tested using Matrix Laboratory (MATLAB) and Transient Systems Simulation (TRNSYS) in an incorporative manner $[21,22]$. MATLAB, developed by MathWorks for numerical computing and programming, and its neural network toolbox were employed to develop the ANN models.

MATLAB was used for: (1) developing ANN models and temperature control logic; (2) predicting indoor temperature (TEMP $\mathrm{PR})$ using the developed ANN models; and (3) determining the heating system operation based on temperature control logic. The decision regarding heating system operation was fed into TRNSYS to operate the heating system. Adopting the heating system operation, TRNSYS produced a new indoor temperature as a result of a working system and the new indoor temperature was transferred to MATLAB.

TRNSYS is an energy simulation software package that can simulate building systems and performance [22]. It was used for: (1) modeling building components and related features (e.g., double or single skin envelopes, heating system, initial thermal conditions, internal load, import of weather data, ventilation rate, and internal load); and (2) calculating indoor temperature (TEMPIN). 
Figure 5 shows the simulation model using the MATLAB and TRNSYS programs. The overall model was developed in TRNSYS and the ANN-based temperature control logic was implemented using Type155. The iterative simulation process was conducted at every cycle which was assigned as one minute in this study.

Figure 5. Modeling procedure of a test building using TRNSYS and MATLAB.

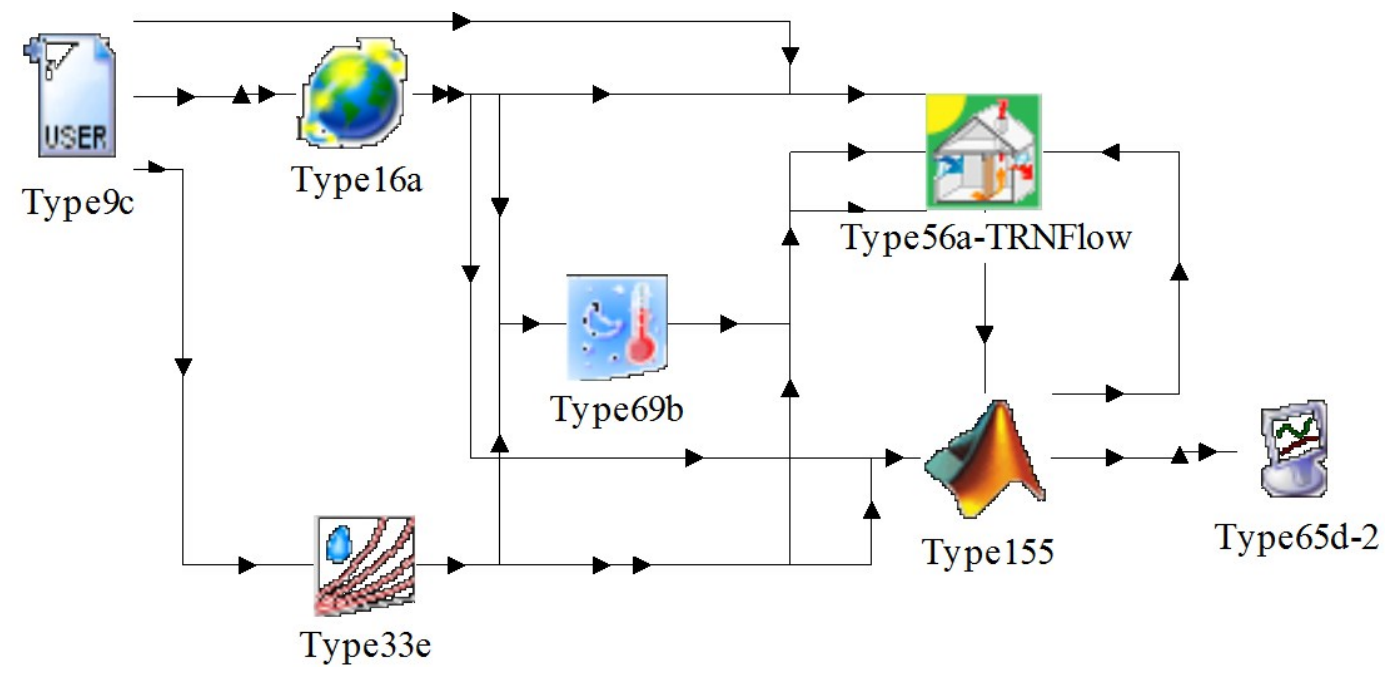

The accuracy of this simulation method was validated in previous studies [8]. The predicted indoor temperature variation by an ANN model was compared with the variation in indoor temperature measured in an actual building. The relationship between the predicted and measured temperature was statistically proven with a significantly smaller root mean square of errors (RMS) at $0.0259 \mathrm{~K}$ than the designated goal of the ANN models $(0.1 \mathrm{~K} \mathrm{RMS})$. Thus, the accuracy of the simulation method was validated for testing the performance of the ANN-based temperature control logic.

\subsection{Building Conditions for Performance Tests}

The developed ANN model performance was tested in one-story buildings with double and single skin envelopes in winter in terms of indoor thermal environments and heating energy efficiency terms. A simplified application to the one-story building was designed to clearly understand the performance of the developed ANN-based temperature control logic.

Figure 6 shows the detailed dimensions of the one-story building with a double skin envelope, which was tested in this study. The building dimensions were $4.2 \mathrm{~m}$ wide, $4.5 \mathrm{~m}$ deep and $3.05 \mathrm{~m}$ high. The main facade where the double skin envelope was installed faced south. The internal and external envelopes were covered with glazing. The distance between the internal and external envelope was $0.9 \mathrm{~m}$ and a cavity space was formed by the two envelopes.

Openings for air inlets and outlets were installed at the top and bottom of internal and external envelopes. The dimensions of the openings were $0.5 \mathrm{~m}$ wide and $0.3 \mathrm{~m}$ high. It was assumed that outdoor air was introduced into cavity space through the air inlet and would pass through the cavity space until it reached the air outlet, when the opening conditions of the air inlet and outlet are controlled. The cavity and indoor temperature were measured in the center of the each space with $1.625 \mathrm{~m}$ height and $1.2 \mathrm{~m}$ height, respectively. 
Figure 6. Layout of tested building. Double skin envelope, (a) plan; (b) section.

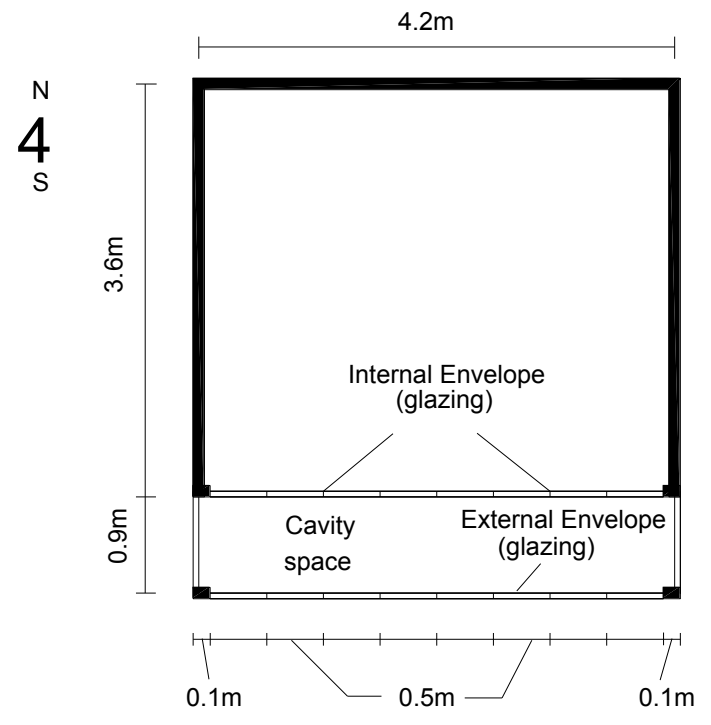

(a)

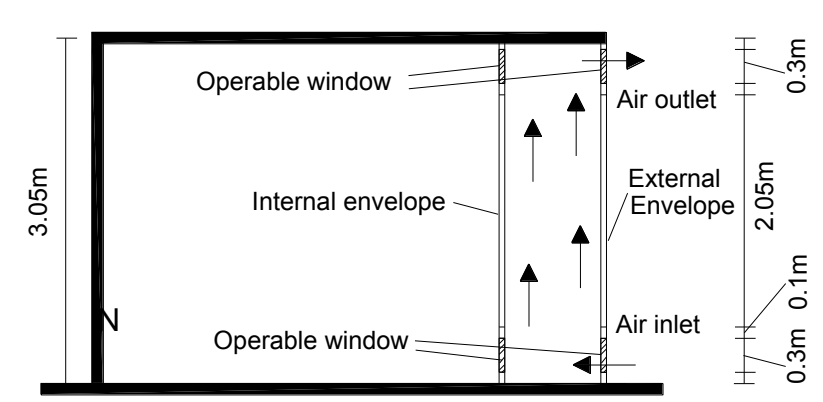

(b)

The one-story building with a single skin envelope is shown in Figure 7. The indoor space dimensions were equal to the dimensions of the building with the double skin envelope. No cavity space existed since the buildings contained a single skin envelope. All conditions, except the cavity, including configurations and structure were identical to those of the building with the double skin envelope.

Figure 7. Layout of tested building (single skin envelope, (a) plan; (b) section).

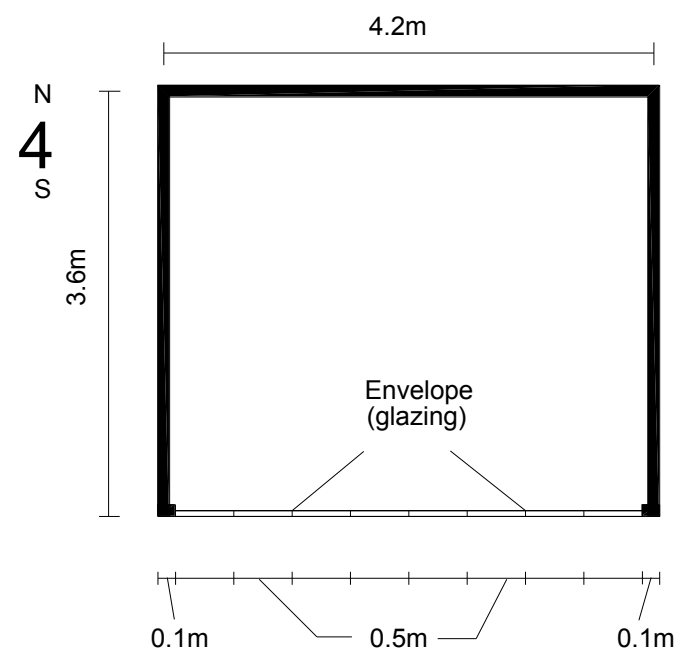

(a)

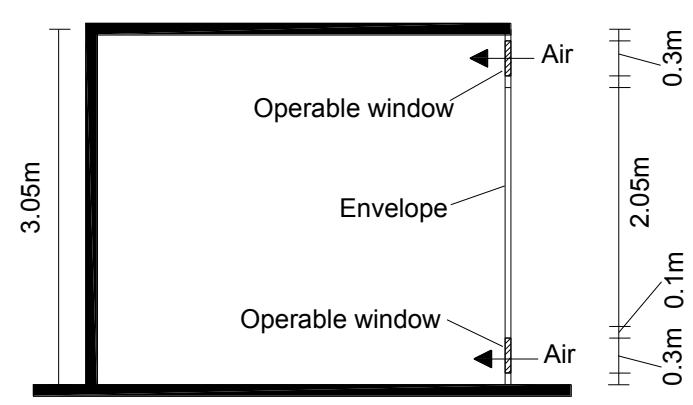

(b)

The two buildings were assumed to be located in Seoul, Korea (latitude: $37.56^{\circ}$, longitude: $126.98^{\circ}$ ). The geometric conditions, thermal properties, heating system and operating conditions of the heating system for the two buildings are summarized in Table 2. Typical Meteorological Year (TMY2) data, which is widely applied for building simulation programs, was used for the test location. 
Table 2. Condition of buildings with single and double skin envelope. TMY2: typical meteorological year. ACH: air change rate per hour.

\begin{tabular}{|c|c|c|}
\hline Item & & Detailed contents \\
\hline Weather data & \multicolumn{2}{|c|}{ TMY2 for Seoul, South Kroea (Latitude: $37.56^{\circ} \mathrm{N}$, Longitude: $\left.126.98^{\circ} \mathrm{E}\right)$} \\
\hline Climate condition & \multicolumn{2}{|c|}{$\begin{array}{l}\text { - Hot and humid in summer: } 23.5^{\circ} \mathrm{C} \text { of air temperature and } 72.7 \% \text { of } \\
\text { relative humidity from June to September on average } \\
\text { - Cold in winter: } 1.7{ }^{\circ} \mathrm{C} \text { of air temperature and } 59.1 \% \text { of relative humidity } \\
\text { from November to February on average }\end{array}$} \\
\hline Dimension & \multicolumn{2}{|c|}{$\begin{array}{l}\cdot 4.2 \mathrm{~m} \text { wide } \times 4.5 \mathrm{~m} \text { deep } \times 3.05 \mathrm{~m} \text { high } \\
\cdot 18.9 \mathrm{~m}^{2}\left(15.12 \mathrm{~m}^{2} \text { for the indoor area, } 3.78 \mathrm{~m}^{2} \text { for the cavity area }\right)\end{array}$} \\
\hline \multirow{5}{*}{$\begin{array}{l}\text { Envelope insulation } \\
\qquad\left(\mathrm{m}^{2} \cdot \mathrm{K} / \mathrm{W}\right)[23]\end{array}$} & Walls & 2.78 \\
\hline & Roof & 5.00 \\
\hline & Floor & 2.44 \\
\hline & \multirow[b]{2}{*}{ Windows } & External envelope : 0.18 (24 mm clear glass) \\
\hline & & $\begin{array}{l}\text { Internal envelope : } 0.77 \\
(6 \mathrm{~mm} \text { gray glass }+16 \mathrm{~mm} \text { argon gas }+6 \mathrm{~mm} \text { gray glass })\end{array}$ \\
\hline Systems applied & \multicolumn{2}{|c|}{ Radiative heating: $7172 \mathrm{~kJ} / \mathrm{h}$ heat supply } \\
\hline System operation ranges [24] & \multicolumn{2}{|c|}{ Heating: $20-23^{\circ} \mathrm{C}$} \\
\hline Internal gain & $\begin{array}{l}\text { - } 2 \text { occupa } \\
\text { - } 2 \text { comput } \\
\text { - } 5 \mathrm{~W} / \mathrm{m}^{2} \mathrm{f} \\
\end{array}$ & $\begin{array}{l}\text { ts with seated, light work, typing } \\
\text { rs and printer } \\
\text { r lighting fixtures }\end{array}$ \\
\hline Infiltration rate [23] & \multicolumn{2}{|c|}{$0.7 \mathrm{ACH}$} \\
\hline
\end{tabular}

The thermal resistances ( $R$-values) of envelope components were $2.78,5.00$ and $2.44 \mathrm{~m}^{2} \cdot \mathrm{K} / \mathrm{W}$ for the wall, roof and floor, respectively. The $R$-values were $0.18 \mathrm{~m}^{2} \cdot \mathrm{K} / \mathrm{W}$ for the internal envelope and $0.77 \mathrm{~m}^{2} \cdot \mathrm{K} / \mathrm{W}$ for the external envelope. A radiative heating system with a $7172 \mathrm{~kJ} / \mathrm{h}$ heat supply capacity was installed for heating. The operation range of the heating system was assumed to be $20-23{ }^{\circ} \mathrm{C}$ to keep the indoor thermal environment within a comfortable range in winter. The infiltration rate into the building was assumed to be 0.7 air change rate per hour $(\mathrm{ACH})$ which is a normal value in buildings. No external obstructions around the building were considered.

The performance tests in this study for the two buildings were conducted using the ANN-based temperature control logic and the conventional non-ANN-based counterpart. Data for the indoor temperature conditions and the heating energy efficiency was collected during January, February, November and December 2013, which represent typical weather conditions of winter for the building sites.

Table 3 summarizes the control algorithms based on the ANN model for the heating system and the internal and external envelope openings. In the ANN-based temperature control logic, as explained in Figure 2, the current conditions of the heating system operation and the optimal opening strategy determined by the ANN models were used as determinants. Based on the comparison between the summation of $T E M P_{\mathrm{IN}}$ and $T E M P_{\mathrm{PR}}$ and the operating range of heating system, the operating signal for the heating system was determined and opening of the internal and external envelopes was followed to optimize the strategy. 
Table 3. Control algorithm of ANN-based temperature control logic.

\begin{tabular}{|c|c|c|c|}
\hline \multicolumn{2}{|c|}{ Current conditions } & \multicolumn{2}{|c|}{ Determined operation } \\
\hline Heating system & $\begin{array}{l}T E M P_{\mathrm{IN}}+T E M P_{\mathrm{PR}} \text { of the } \\
\text { optimal opening strategy }\end{array}$ & Heating system & Opening strategy \\
\hline \multirow{2}{*}{ On } & $\leq 23{ }^{\circ} \mathrm{C}$ & On & \multirow{4}{*}{$\begin{array}{l}\text { Conduct optimal } \\
\text { opening strategy }\end{array}$} \\
\hline & $>23^{\circ} \mathrm{C}$ & Off & \\
\hline \multirow{2}{*}{ Off } & $\geq 20^{\circ} \mathrm{C}$ & Off & \\
\hline & $<20^{\circ} \mathrm{C}$ & On & \\
\hline
\end{tabular}

The conventional non-ANN-based temperature control logic applied a similar process (Table 4). Current heating system conditions and the indoor temperature were used as determinants. The operating signal was determined for the heating system based on the comparisons between the indoor temperature and the operation range of the system.

Table 4. Control algorithm of conventional non-ANN-based temperature control logic.

\begin{tabular}{|c|c|c|c|}
\hline \multicolumn{2}{|c|}{ Current conditions } & \multicolumn{2}{|r|}{ Determined operation } \\
\hline Heating system & $T E M P_{\text {IN }}$ & Heating system & Opening strategy \\
\hline \multirow{2}{*}{ On } & $\leq 23^{\circ} \mathrm{C}$ & On & \multirow{4}{*}{$\begin{array}{l}- \text { When } T E M P_{\mathrm{CAV}}\left(T E M P_{\mathrm{OUT}} \text { for } \mathrm{SSE}\right)>26^{\circ} \mathrm{C} \text {, } \\
\text { internal openings are opened and external openings are } \\
\text { closed (openings are opened for SSE). } \\
\text { - When } T E M P_{\mathrm{CAV}}\left(T E M P_{\mathrm{OUT}} \text { for } \mathrm{SSE}\right) \leq 26{ }^{\circ} \mathrm{C} \text {, } \\
\text { internal openings are closed and external openings are } \\
\text { closed (openings are closed for SSE). }\end{array}$} \\
\hline & $>23{ }^{\circ} \mathrm{C}$ & Off & \\
\hline & $\geq 20^{\circ} \mathrm{C}$ & Off & \\
\hline Off & $<20^{\circ} \mathrm{C}$ & On & \\
\hline
\end{tabular}

The opening strategy for the envelope was determined by the intuitively designed criteria. For example, in double skin envelope buildings, if the temperature of the cavity space was over $26^{\circ} \mathrm{C}$, the openings at the internal envelope were open and the openings at the external envelope were closed. A similar algorithm was applied in the single skin envelope buildings, while the only difference was the application of outdoor temperature to determine the surface opening conditions.

\section{Results and Discussion}

\subsection{Influence of Control Logic on Thermal Comfort}

The comparative performance of the ANN-based and the conventional non-ANN-based logic was examined to analyze the influence of control logic on indoor air temperature variation. Figures 8 and 9 show the indoor temperature profiles and the heating system operation in the single skin and double skin enveloped buildings by two control logic for a selected week in January. 
Figure 8. Indoor temperature and operation of heating system (Single Skin Envelope, 8-14 January 2013). (a) Non-ANN-based control; (b) ANN-based control.

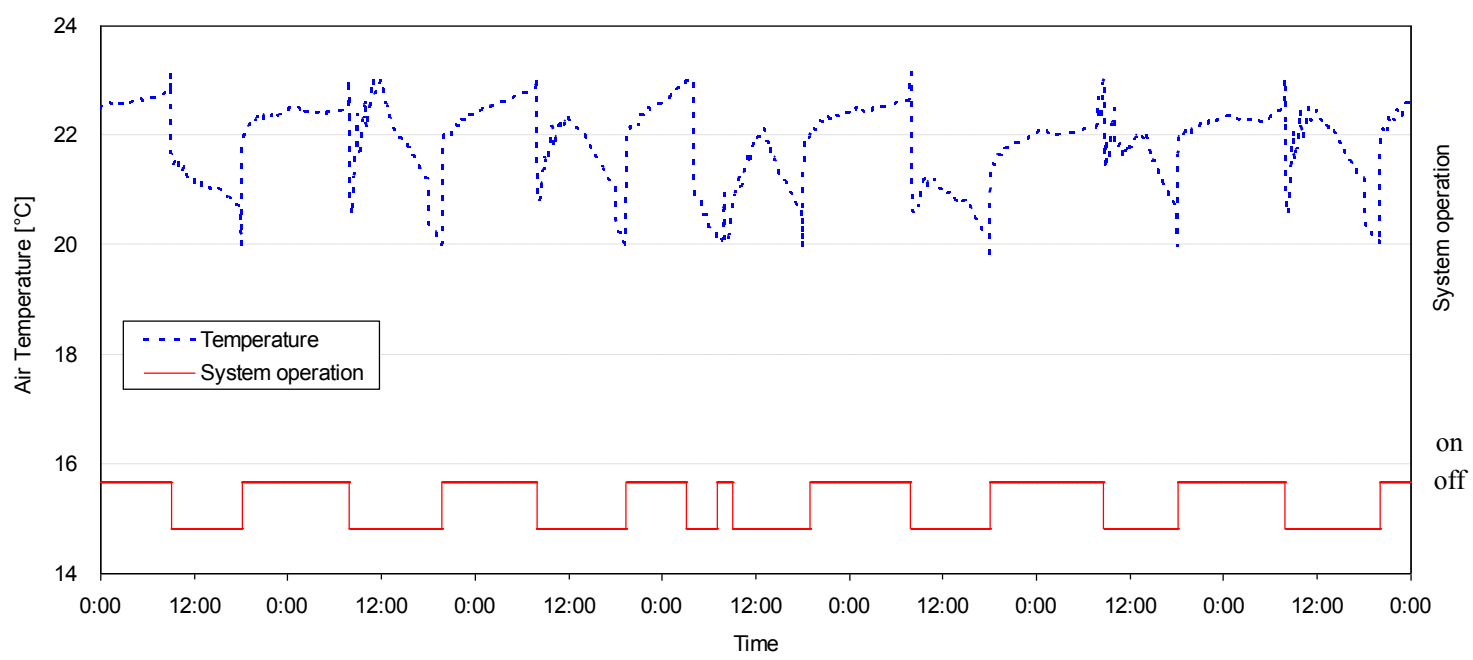

(a)

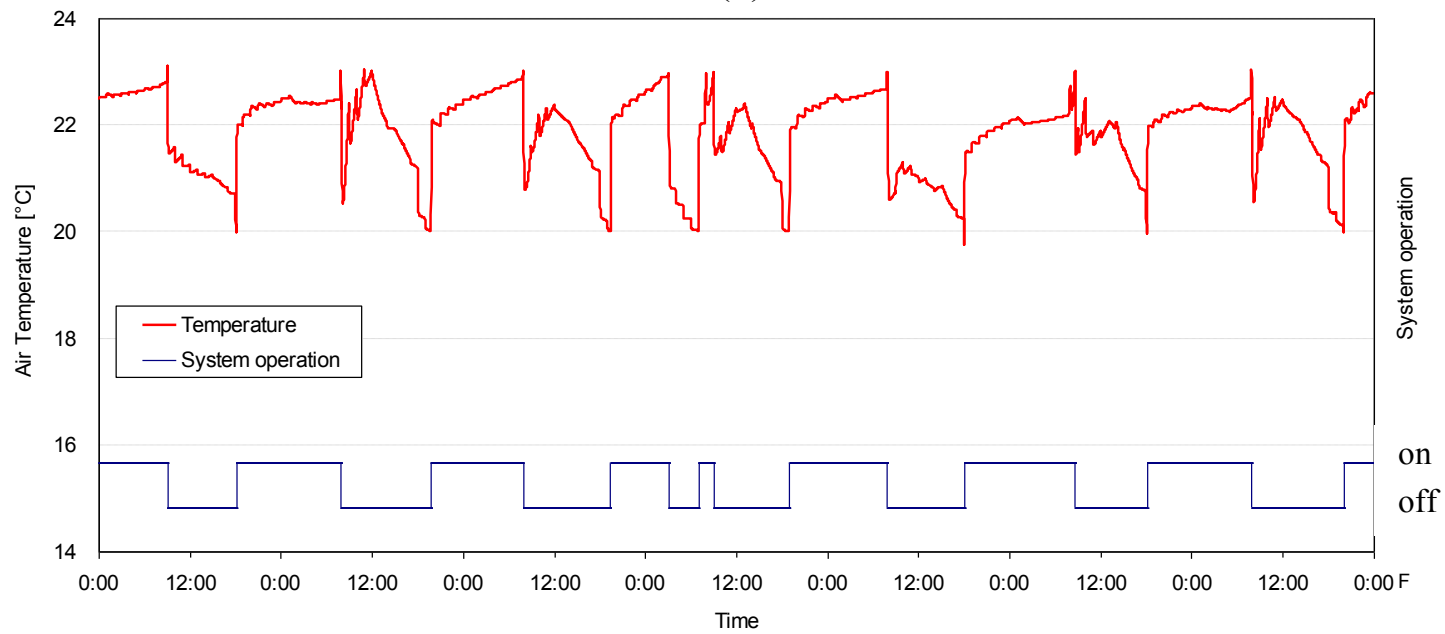

(b)

The indoor temperature conditions and system operation by ANN-based and non-ANN-based logic showed slightly different patterns since the ANN-based logic predetermined the operation of the heating system. In both single skin and double skin enveloped buildings, temperatures by non-ANN-based logic deviated beyond the operating range at every on/off moment of the heating system. In comparison, the temperatures determined by ANN-based logic stayed within the operating range in more cases.

Similarly, in Figures 10 and 11, which present detailed movement on 1 January 2013 as an example, the difference of the indoor temperature and the heating system operation are more clearly compared. The heating system by the ANN-based logic was turned off earlier than the non-ANN-based logic, thus the indoor temperature did not rise above the upper limit of the operating range $\left(23^{\circ} \mathrm{C}\right)$ (Figure 10). 
Figure 9. Indoor temperature and operation of heating system (Double Skin Envelope, 8-14 January 2013). (a) Non-ANN-based control; (b) ANN-based control.

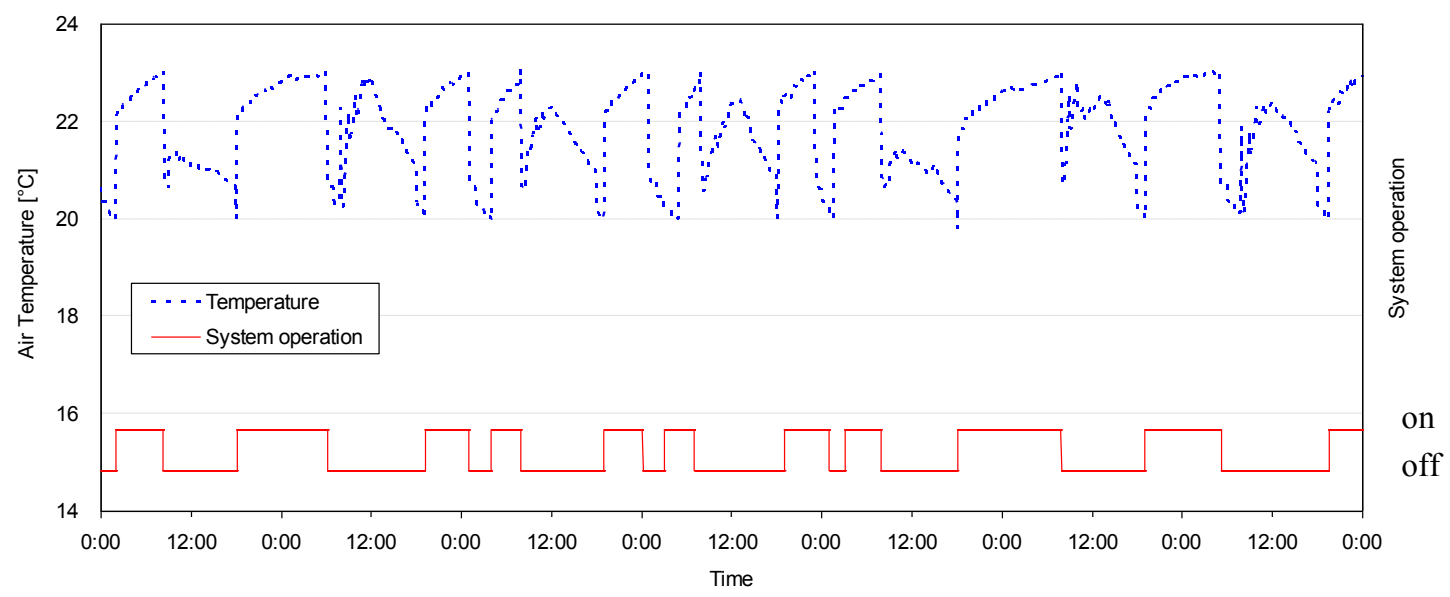

(a)

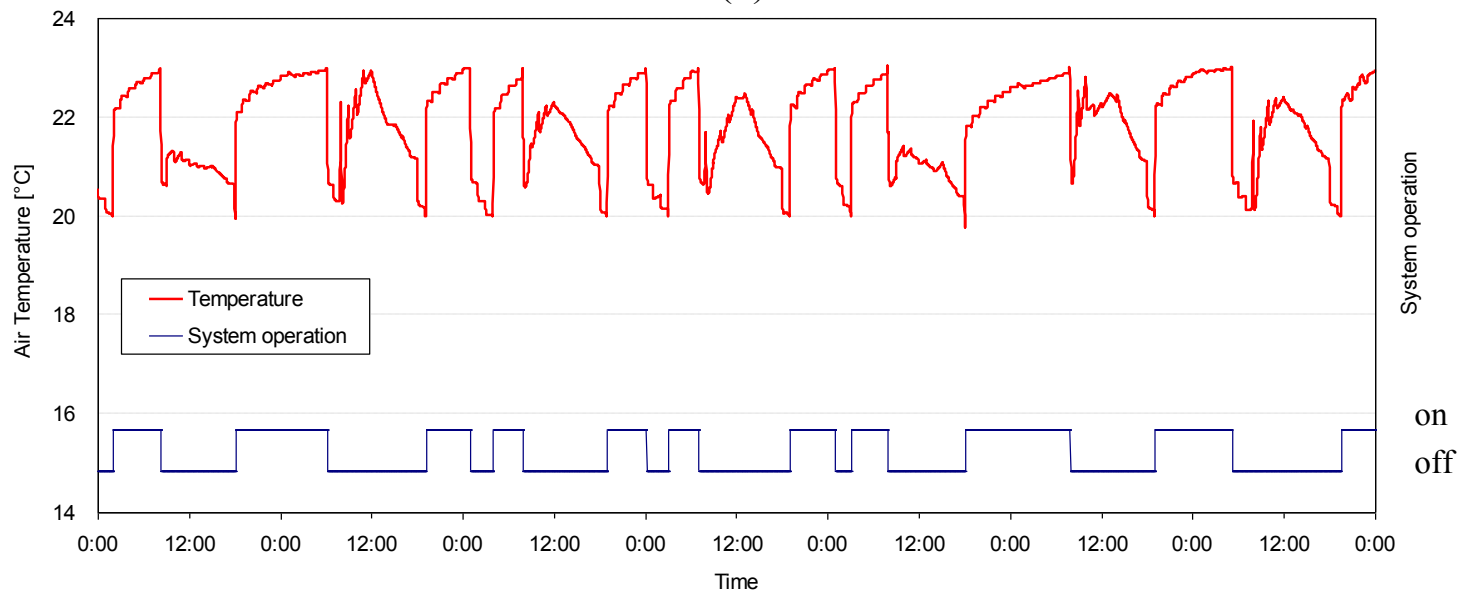

(b)

In addition, the ANN-based temperature control logic was predetermined to turn on the heating system before the indoor temperature reached the lower limit of the operating range $\left(20^{\circ} \mathrm{C}\right)$ (Figure 11). Thus, the ANN-based heating system began to work earlier than the conventional non-ANN-based temperature control logic. As a result, indoor temperature with the ANN-based logic did not drop below $20^{\circ} \mathrm{C}$ while that controlled by the conventional logic went below $20^{\circ} \mathrm{C}$, which was determined to be an uncomfortable temperature condition.

For the whole test period, the openings in the external envelope in the double skin enveloped building were always closed by the control logic. This indicates that the optimal opening strategy determined by ANN models at every control cycle required closing the openings at the external envelope. The openings in the internal envelope were opened for a total of $41 \mathrm{~min}$ by the ANN-based logic, but were opened for $0 \mathrm{~min}$ by the conventional non-ANN-based logic. The openings in the internal envelope all occurred in November 2013 when the cavity temperatures were relatively higher than they were in other periods. In this period, the ANN models determined that opening inner openings and closing outer openings was the optimal strategy. 
Figure 10. Indoor temperature and operation of heating system (Single skin envelope, 1 January 2013).

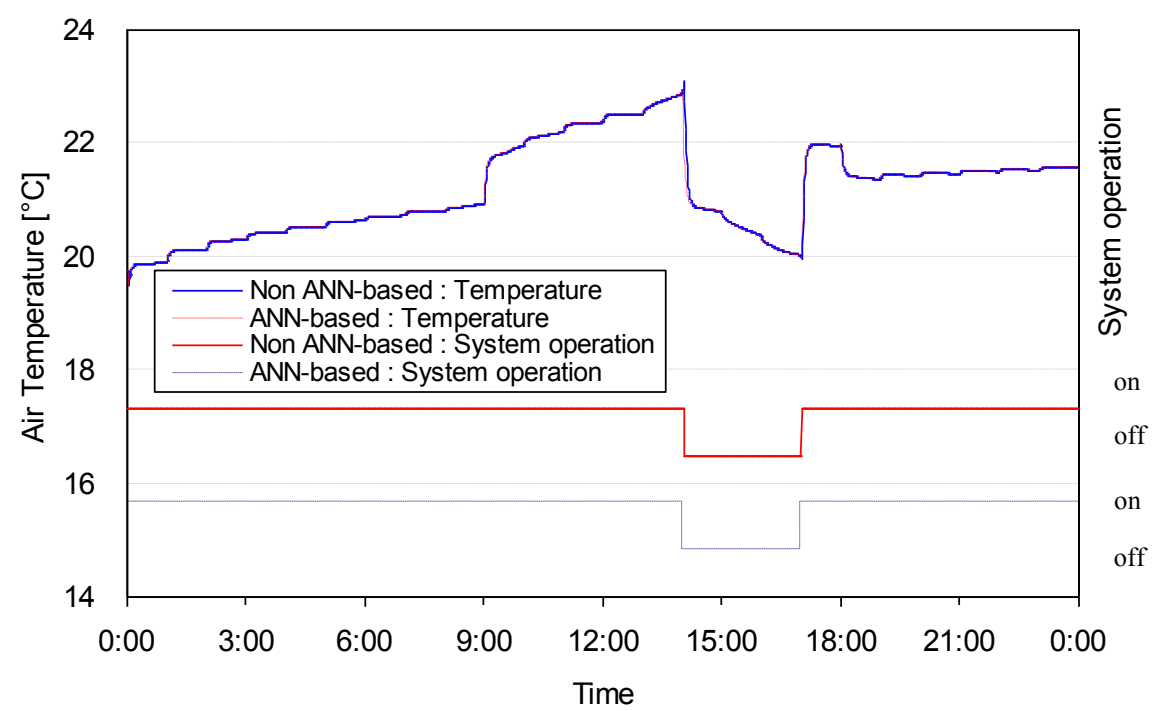

Figure 11. Indoor temperature and operation of heating system (Double skin envelope, 1 January 2013).

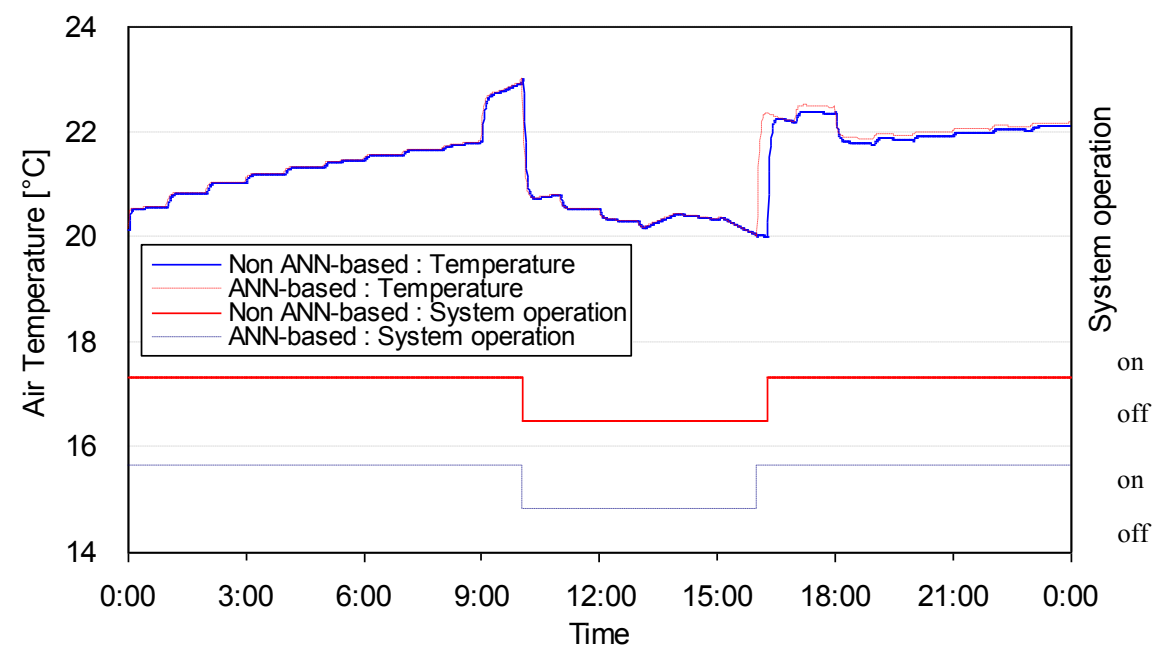

The average and the comfortable periods of the indoor temperature were compared for the ANN-based logic and the conventional non-ANN-based logic in Figures 12 and 13, respectively. For the entire test period, the average indoor temperatures determined by the non-ANN-based and ANN-based logic were similar in both building types. The average temperatures for the whole test period were $21.97{ }^{\circ} \mathrm{C}$ and $21.98{ }^{\circ} \mathrm{C}$ in the single skin enveloped building and $22.05^{\circ} \mathrm{C}$ and $22.06{ }^{\circ} \mathrm{C}$ in the double skin enveloped building, respectively (Figure 12).

However, the indoor temperature comfortable period was increased by the ANN-based temperature control logic for all months in both building types. The amount of the increase was $87 \mathrm{~min}$ in the single skin enveloped building and $346 \mathrm{~min}$ in the double skin enveloped building, which is $0.05 \%$ and $0.2 \%$ of the total period, from $86.75 \%$ to $86.80 \%$ and from $86.14 \%$ to $86.34 \%$, respectively (Figure 13 ). 
Figure 12. Mean indoor temperature by four control logic.

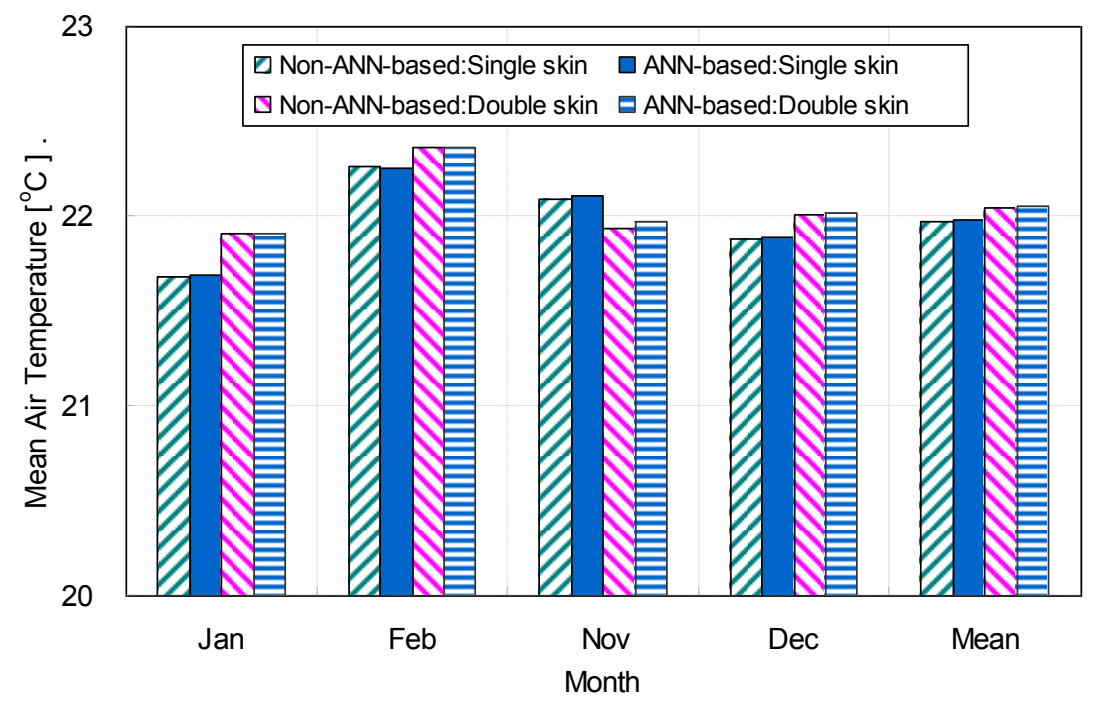

Figure 13. Comfortable period of indoor air temperature by four control logic.

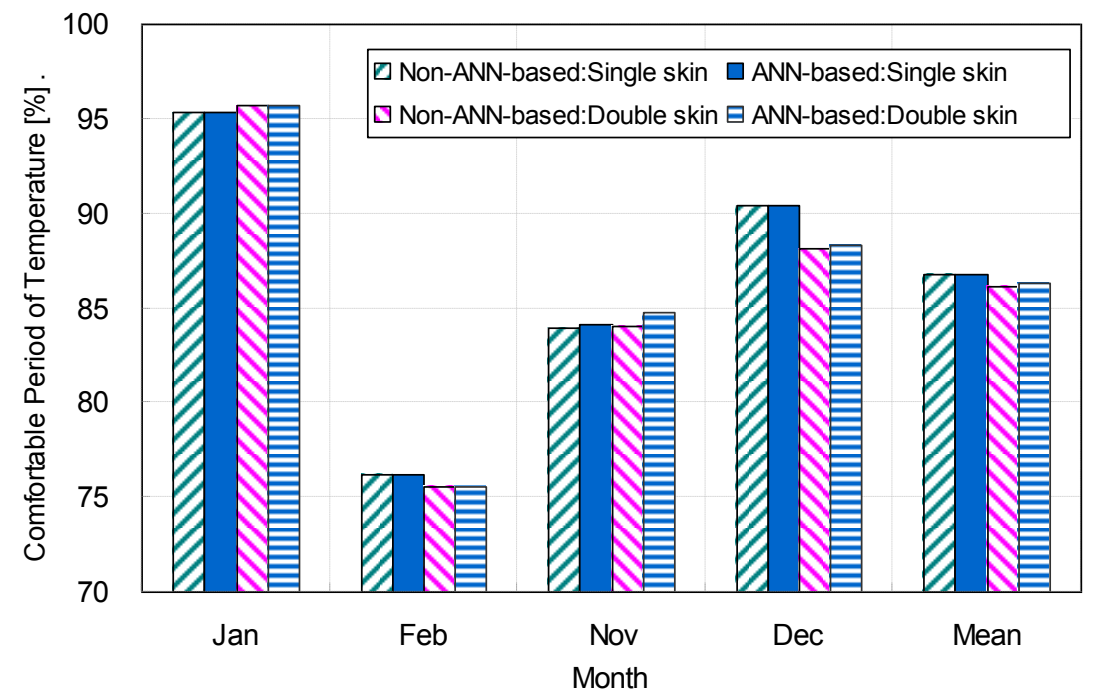

\subsection{Influence of Control Logic on Thermal Stability}

The increase in the comfortable period achieved by the ANN-based logic was connected to the decrease in overshoots and undershoots outside of the operating range (Table 5). The number of overshoots and undershoots outside of the operating range were reduced by ANN-based logic except for overshoots in November for both building types. The entire reduction for the whole period was 19 times (overshoots) and 15 times (undershoots) in the single skin enveloped building and 11 times (overshoots) and 28 times (undershoots) in the double skin enveloped building. This indicates that the indoor temperature was conditioned and was more stable within the operating range due to the predictive controls of the ANN-based logic.

Similarly, the ratio of overshoots and undershoots outside of the comfort range over the total number of overshoots and undershoots by the heating system was reduced by the ANN-based control logic. Every overshoot and undershoot left the operating range by the conventional non-ANN-based logic, while these percentiles were significantly reduced by the ANN-based logic, because ANN-predicted 
temperature was employed in the control logic. The amount of monthly reduction varied from $8.11 \%$ to $26.67 \%$ in the single skin enveloped building and from $2.08 \%$ to $35.72 \%$ in the double skin enveloped building. In summary, the increase in the comfortable period as well as the decrease in the number and ratio of overshoots and undershoots supported the superiority of the ANN-based temperature control logic.

Table 5. Comparison of thermal performance between the ANN-based and non-ANN-based temperature control logic.

\begin{tabular}{|c|c|c|c|c|c|}
\hline \multirow[b]{2}{*}{$\begin{array}{l}\text { Thermal } \\
\text { performance } \\
\text { components }\end{array}$} & \multirow[b]{2}{*}{ Month } & \multicolumn{2}{|c|}{ Single skin envelope } & \multicolumn{2}{|c|}{ Double skin envelope } \\
\hline & & $\begin{array}{l}\text { ANN-based } \\
\text { temperature } \\
\text { control logic }\end{array}$ & $\begin{array}{c}\text { Non-ANN-based } \\
\text { temperature } \\
\text { control logic } \\
\end{array}$ & $\begin{array}{l}\text { ANN-based } \\
\text { temperature } \\
\text { control logic }\end{array}$ & $\begin{array}{l}\text { Non-ANN-based } \\
\text { temperature } \\
\text { control logic } \\
\end{array}$ \\
\hline \multirow{5}{*}{$\begin{array}{l}\text { Number of overshoot } \\
\text { and undershoot out of } \\
\text { the operating range } \\
\text { (overshoot/undershoot) }\end{array}$} & January & $30 / 28$ & $35 / 35$ & $35 / 39$ & $44 / 44$ \\
\hline & February & $25 / 22$ & $30 / 29$ & $33 / 24$ & $34 / 33$ \\
\hline & November & $29 / 31$ & $28 / 28$ & $41 / 27$ & $40 / 40$ \\
\hline & December & $28 / 34$ & $38 / 38$ & $46 / 47$ & $48 / 48$ \\
\hline & Total & $112 / 115$ & $131 / 130$ & $155 / 137$ & $166 / 165$ \\
\hline \multirow{5}{*}{$\begin{array}{l}\text { Ratio of overshoot and } \\
\text { undershoot out of the } \\
\text { operating range (\%) } \\
\text { (overshoot/undershoot) }\end{array}$} & January & $83.33 / 77.78$ & $100 / 100$ & $79.55 / 88.64$ & $100 / 100$ \\
\hline & February & $80.65 / 73.33$ & $100 / 100$ & $97.06 / 72.73$ & $100 / 100$ \\
\hline & November & $82.86 / 88.57$ & $100 / 100$ & $93.02 / 64.28$ & $100 / 100$ \\
\hline & December & $75.68 / 91.89$ & $100 / 100$ & $95.83 / 97.92$ & $100 / 100$ \\
\hline & Total & $80.58 / 83.33$ & $100 / 100$ & $91.12 / 82.04$ & $100 / 100$ \\
\hline
\end{tabular}

\subsection{Influence of Control Logic on Energy Consumption}

The energy consumption used for the space shown in Figures 6 and 7 was analyzed to examine the effect of control logic on building energy efficiency in winter. The amount of heat supply to each space surrounded by single and double skin envelopes is compared in Figure 14.

Figure 14. Amount of heat supply by four control logic.

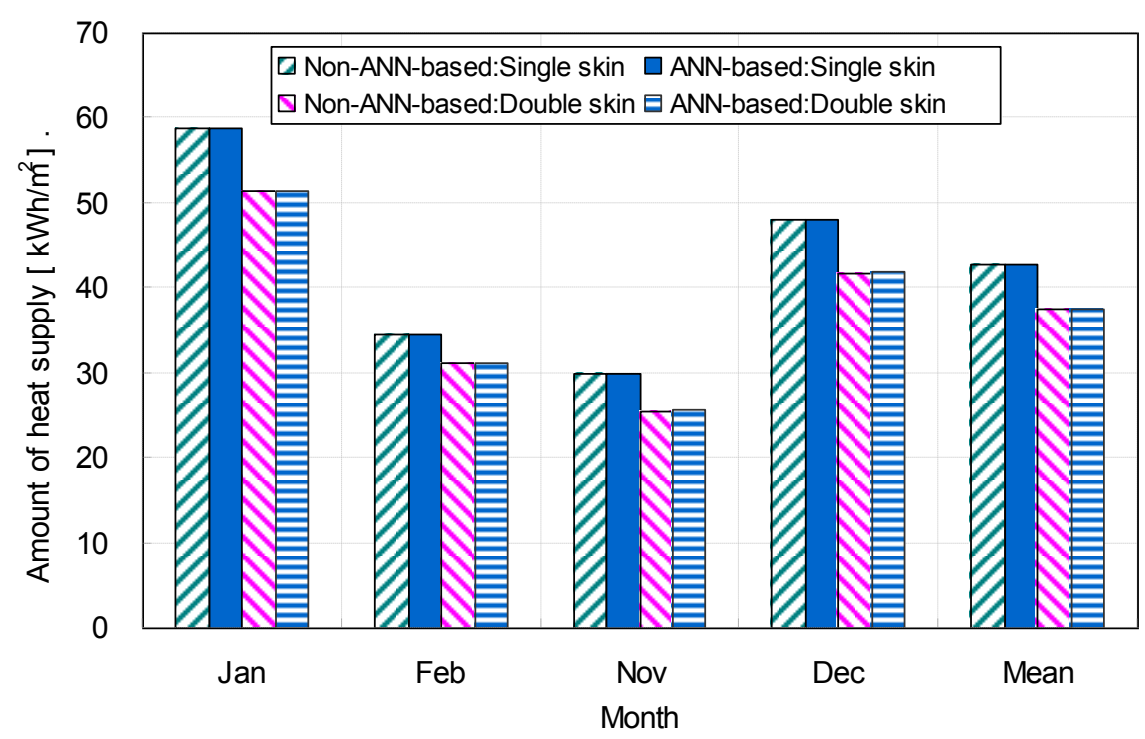


Overall, less energy was required to maintain the indoor temperature within a designated comfort range when the double skin envelopes were used for buildings. When the non-ANN-based control logic was employed to control indoor temperature within a comfort range, the amount of heat supply ranged from $29.97 \mathrm{~kW} / \mathrm{m}^{2}$ to $58.76 \mathrm{~kW} / \mathrm{m}^{2}$ and from $25.62 \mathrm{~kW} / \mathrm{m}^{2}$ to $51.39 \mathrm{~kW} / \mathrm{m}^{2}$ for the single and double skin enveloped buildings, respectively. The heat supply was reduced by $12.47 \%$ on average during the four months, as the envelope was changed from single to double skin.

The energy consumption ranged from $29.87 \mathrm{~kW} / \mathrm{m}^{2}$ to $58.73 \mathrm{~kW} / \mathrm{m}^{2}$ and $25.73 \mathrm{~kW} / \mathrm{m}^{2}$ to $51.39 \mathrm{~kW} / \mathrm{m}^{2}$ for the single skin and double skin envelopes, respectively, when the ANN-based control logic was used for primary thermal control. The heat supply reduction by ANN control logic during the same four months was $12.32 \%$ on average, as the envelope was reinforced to the double skin condition.

The ANN-based temperature control logic did not result in significantly improved energy efficiency of the heating system over the non-ANN-based logic. The reduced amount in the single skin envelope condition was $0.105 \mathrm{~kW} / \mathrm{m}^{2}(0.06 \%)$. However, slightly more energy was required when the ANN models were applied in the double skin envelope condition, in which $0.152 \mathrm{~kW} / \mathrm{m}^{2}(0.10 \%)$ more heating energy was more consumed compared to the conventional logic.

There are two major reasons for this phenomenon. The primary reason is that the average indoor temperature during the test period was kept higher when the ANN-based logic was applied, as previously described in Figure 12. To maintain a higher temperature, the heating system worked for a longer period of time. The second reason is the time compensation between operating and non-operating time when the ANN-based temperature control logic was applied. When the ANN-based logic was applied, the heating system stopped working earlier in a predictive manner than by the conventional logic. The working time was shorter which saved heating energy.

However, the heating system started working earlier as well, resulting in a reduced non-working period and an increase in heating energy. In other words, when the ANN-based logic was applied, the working time in each cycle was shorter while the number of operating cycles was increased. Therefore, the cumulative working time was similar to that of the conventional logic. Based on these two factors, the ANN-based temperature control logic did not guarantee improved energy-efficiency. However, as explained in the previous section, the ANN-based temperature control logic presented its superiority for providing more comfortable and stable temperature conditions over the non-ANN-based counterpart.

\section{Conclusions}

This study proposes an indoor air temperature control method to maintain optimal thermal comfort using integrated heating system control and envelope opening. The ANN-based temperature control logic was developed for predictive and adaptive thermal control. The comparative performance tests for the ANN-based temperature control logic and the non-ANN-based counterpart were conducted numerically using a computer simulation. The findings of this study are summarized as follows:

(1) The average ANN-based and non-ANN-based logic temperatures were similar. However, the ANN-based temperature control logic provided slightly advanced comfortable temperature conditions than the conventional non-ANN-based temperature control logic. Using the ANN models, the system operation was able to be predetermined, thus the indoor temperature could be better maintained within the operating range of the system. The increase in comfortable period 
was $87 \mathrm{~min}$ and $346 \mathrm{~min}$ for the single skin envelope and double skin envelope conditions, respectively, which accounted for $0.05 \%$ and $0.20 \%$ of the total test period.

(2) The ANN-based logic provided a significant improvement in the stability of the temperature conditions. Overshoots and undershoots outside of the operating range were reduced by the ANN-based logic as much as 19 times for overshoots and 15 times for undershoots in the single skin envelope condition and 11 times for overshoots and 28 times for undershoots in the double skin envelope condition.

(3) The ratio of overshoots and undershoots outside of the comfort range over the total number of overshoots and undershoots by the heating system was reduced by the ANN-based control logic. The amount of monthly reduction varied from $8.11 \%$ to $26.67 \%$ in the single skin envelope conditions and from $2.08 \%$ to $35.72 \%$ in the double skin envelope conditions.

(4) Less heating energy was consumed in the double skin envelope condition than in the single skin envelope condition. The reduction was $12.47 \%$ for the non-ANN-based logic and $12.32 \%$ for the ANN-based logic, which proved that double skin enveloped buildings have the ability to reduce heating energy in winter. However, the ANN-based temperature control logic did not guarantee improved heating system energy efficiency. This finding was attributable to the more highly maintained indoor temperature and the time compensation by ANN-based control logic.

In summary, based on the increased stability and comfortable period of indoor temperature with the decreased number and ratio of overshoots and undershoots of temperature, the ANN-based temperature control logic is able to maintain the indoor temperature more comfortably and with more stability within the operating range due to the predictive and adaptive features of ANN models. Further studies that apply the developed logic to actual buildings under diverse weather conditions are necessary.

By conducting performance tests for these diverse applications, the applicability of the developed logic will be fully demonstrated in terms of thermal quality and energy efficiency. In addition, further studies are necessary to investigate the productivity improvement in the more comfortably conditioned environments and to examine the economic benefits of the proposed logic.

\section{Acknowledgments}

This research was supported by the Basic Science Research Program through the National Research Foundation of Korea (NRF) funded by the Ministry of Education, Science and Technology (grant number: 2012R1A1A1005275).

\section{Nomenclature}

TEMP $\quad$ indoor air temperature $\left({ }^{\circ} \mathrm{C}\right)$

$\triangle T E M P_{\mathrm{IN}} \quad$ indoor air temperature change from the preceding control cycle $\left({ }^{\circ} \mathrm{C}\right)$

TEMP OUT outdoor air temperature $\left({ }^{\circ} \mathrm{C}\right)$

TEMP ${ }_{\mathrm{CAV}} \quad$ cavity air temperature $\left({ }^{\circ} \mathrm{C}\right)$

TEMP $\mathrm{PR} \quad$ predicted amount of air temperature overshoot or undershoot $\left({ }^{\circ} \mathrm{C}\right)$

$I_{N P U T_{\mathrm{ACT}}}$ actual input value

INPUT $T_{\mathrm{MAX}}$ maximum input value 
INPUTMIN minimum input value

$N_{\mathrm{d}} \quad$ number of training data sets

$N_{\mathrm{i}} \quad$ number of input neurons

$N_{\mathrm{h}} \quad$ number of hidden neurons

No number of output neuron

\section{Author Contributions}

All authors participated in preparing the research from the beginning to ends, such as establishing research design, method and analysis. All authors discussed and finalized the analysis results to prepare manuscript according to the progress of research.

\section{Conflicts of Interest}

The authors declare no conflict of interest.

\section{References}

1. Lee, E.; Selkowitz, S.; Bazjanac, S.; Kholer, C. High-Performance Commercial Building Facades; LBNL Report-50502; Lawrence Berkeley National Laboratory: Berkeley, CA, USA, 2011.

2. Shameri, M.; Alghoul, M.; Sopian, K.; Fauzi, M.; Zain, M.; Omkalthum, E. Perspectives of double skin facade systems in buildings and energy saving. Renew. Sustain. Energy Rev. 2011, 15, 1468-1475.

3. Kim, Y.; Lee, J.; Kim, S. Effect of double skin envelopes on natural ventilation and heating in office buildings. Energy Build. 2011, 43, 2118-2126.

4. Kim, Y.; Kim, S.; Shin, S.; Sohn, J. Contribution of natural ventilation in a double skin envelope to heating load reduction in winter. Build. Environ. 2009, 44, 2236-2244.

5. Saelens, D.; Roels, S.; Hens, H. Strategies to improve the energy performance of multiple-skin facades. Build. Environ. 2008, 43, 638-650.

6. Gratia, E.; Herde, A. Are energy consumptions decreased with the addition of a double-skin. Energy Build. 2007, 39, 605-619.

7. Fallahi, A.; Haghighat, F.; Elsadi, H. Energy performance assessment of double-skin facade with thermal mass. Energy Build. 2010, 4, 1499-1509.

8. Moon, J.; Yoon, S.; Kim, S. Development of an artificial neural network model based thermal control logic for double skin envelopes in winter. Build. Environ. 2013, 61, 149-159.

9. Stergiou, C.; Siganos, D. Neural Networks. Available online: http://www.doc.ic.ac.uk/ nd/ surprise_96/journal/vol4/cs11/report.html (accessed on 10 November 2012).

10. Moon, J.; Kim, J. ANN-based thermal control models for residential buildings. Build. Environ. 2010, 45, 1612-1625.

11. Yang, I.; Yeo, M.; Kim, K. Application of artificial neural network to predict the optimal start time for heating system in building. Energy Convers. Manag. 2003, 44, 2791-2809.

12. Yang, I.; Kim, K. Development of artificial neural network model for the prediction of descending time of room air temperature. Int. J. Air-Cond. Refrig. 2000, 12, 1038-1048. 
13. Argiriou, A.; Bellas-Velidis, I.; Kummert, M.; Andre, P. A neural network controller for hydronic heating systems of solar buildings. Neural Netw. 2004, 17, 427-440.

14. Morel, N.; Bauer, M.; El-Khoury, M.; Krauss, J. NEUROBAT, a predictive and adaptive heating control system using artificial neural networks. Int. J. Sol. Energy 2001, 21, 161-201.

15. Lee, J.; Yeo, M.; Kim, K. Predictive control of the radiant floor heating system in apartment buildings. J. Asian Archit. Build. Eng. 2002, 1, 105-112.

16. Lee, J.; Yang, I.; Song, S.; Kim, H.; Kim, K. A study of the predictive control of the Ondol system in apartments. In Proceedings of the International Building Performance Simulation Association, Kyoto, Japan, 13-15 September 1999; pp. 215-222.

17. Ruano, A.; Crispim, E.; Conceicao, E.; Lucio, M. Prediction of building's temperature using neural networks models. Energy Build. 2006, 38, 682-694.

18. Kalogirou, S.; Bojic, M. Artificial neural networks for the prediction of the energy consumption of a passive solar building. Energy 2000, 25, 479-491.

19. Moon, J.; Chin, K.; Kim, S. Optimum application of thermal factors to artificial neural network models for improvement of control performance in double skin-enveloped buildings. Energies 2013, 6, 4223-4245.

20. Moon, J.; Chang, J.; Kim, S. Determining adaptability performance of artificial neural network-based thermal control logics for envelope conditions in residential buildings. Energies 2013, 6, 3548-3570.

21. MathWorks. MATLAB 14. Available online: http://www.mathworks.com/ (accessed on 17 March 2010).

22. University of Wisconsin. TRNSYS16.1. 2010-12. Available online: http://sel.me.wisc.edu/trnsys/ (accessed on 5 December 2010).

23. Design of Environmental-Friendly Houses and Guidelines for Performance Evaluation; Ministry of Land, Transport and Maritime Affairs of Korea: Gwachon, Korea, 2009.

24. Energy-Efficient Design of Low-Rise Residential Buildings; ASHRAE Standard 90.2-2004; American Society of Heating, Refrigerating and Air-Conditioning Engineers Inc.: Atlanta, GA, USA, 2004.

(C) 2014 by the authors; licensee MDPI, Basel, Switzerland. This article is an open access article distributed under the terms and conditions of the Creative Commons Attribution license (http://creativecommons.org/licenses/by/4.0/). 